\title{
Nacionalização Partidária e Estratégias Eleitorais no Presidencialismo de Coalizão*
}

\section{André Borges}

Instituto de Ciência Política, Universidade de Brasília (UnB), Brasília, DF, Brasil. E-mail: andrebc@unb.br.

$\mathrm{E}$ ste artigo pretende investigar o impacto do ciclo eleitoral presidencial e das instituições federativas sobre a nacionalização das eleições legislativas em contexto multipartidário. Mais especificamente, o objetivo é entender como a dinâmica da competição eleitoral nas eleições para o Executivo nacional e estadual atua sobre as estratégias de nacionalização ou regionalização dos partidos no território brasileiro.

O conceito de nacionalização partidária tem sido utilizado na literatura comparativa para aferir o grau em que a variação da votação dos partidos entre os diferentes distritos se aproxima ou se distancia da votação nacional. Sistemas nacionalizados seriam aqueles em que a força eleitoral dos partidos se distribui homogeneamente entre os distritos (Jones e Mainwaring, 2003; Chhibber e Kollman, 2004; Brancati, 2008; Morgenstern et al., 2009). Conforme a utilização consagrada na literatura, adotou-se neste artigo o termo "nacionalização partidária" com respeito às eleições para a Câmara dos Deputados, uma vez que a disputa legislativa nacional é a que indica mais claramente o efetivo nível de apoio aos partidos e sua distribuição no território.

\footnotetext{
* Versões anteriores deste artigo se beneficiaram de comentários e críticas de colegas a quem sou grato: Mathieu Turgeon, Pedro Neiva, Lara Mesquita e Jairo Nicolau. Agradeço também às excelentes sugestões feitas pelos pareceristas anônimos da DADOS Revista de Ciências Sociais. O artigo é resultado de projeto de pesquisa apoiado pelo Conselho Nacional de Desenvolvimento Científico e Tecnológico (CNPq).
}

DADOS - Revista de Ciências Sociais, Rio de Janeiro, vol. 58, nํ3, 2015, pp. 651 a 688. 
Entre os fatores institucionais que condicionam o grau de nacionalização partidária destacam-se a eleição direta para o chefe do Executivo e o grau de descentralização dos governos. A literatura comparada argumenta que a proximidade temporal entre a eleição presidencial e as eleições legislativas resulta em uma espécie de "efeito darwiniano" sobre o sistema partidário, selecionando os partidos capazes de nacionalizar as suas votações e mobilizar uma maioria do eleitorado nacional. Dadas certas condições, a disputa presidencial assumiria formato bipartidário, de modo que partidos incapazes de lançar candidatos competitivos à Presidência acabariam obrigados a se vincular a um dos dois principais contendores para garantir a sua sobrevivência eleitoral (Golder, 2006; Hickens e Stoll, 2011; Shugart e Carey, 1992).

Este efeito, no entanto, depende do grau de centralização do governo. Isto porque, uma vez colocados em marcha processos de centralização da autoridade governamental e perda de prerrogativas e poderes dos governos subnacionais, os eleitores devem se tornar mais inclinados a buscar, por meio do voto, influir nas decisões tomadas no plano nacional de governo (Chhibber e Kollman, 2004). Dentro desta lógica, partidos competitivos nas eleições estaduais mas incapazes de disputar a Presidência acabariam perdendo espaço para os partidos predominantes na arena presidencial. Os dois efeitos combinados - nacionalização dos partidos presidenciais e perda do peso relativo dos partidos incapazes de competir nacionalmente - resultariam na nacionalização agregada do sistema partidário.

Em sistemas políticos relativamente descentralizados, em que governos subnacionais influenciam na produção de políticas e na dinâmica partidária nacional, o efeito de seleção natural da competição presidencial tende a operar de forma distinta, pois os partidos não competitivos na corrida à presidência podem sobreviver disputando eleições estaduais. A questão que se coloca, portanto, é saber como diferentes partidos respondem aos incentivos à nacionalização provenientes da competição presidencial em um sistema federativo. A literatura sobre nacionalização partidária não traz uma resposta a esse tipo de indagação, dado o seu enfoque sobre os efeitos sistêmicos de fatores institucionais como o ciclo eleitoral presidencial, as regras eleitorais e o federalismo.

A proposta do artigo é, precisamente, "desagregar" o conceito de nacionalização partidária, com o desenvolvimento de um modelo 
tipológico de estratégias partidárias em sistemas presidencialistas com múltiplos níveis de governo. O pressuposto básico do modelo é que partidos que buscam expandir a sua base eleitoral no território enfrentam uma escolha estratégica fundamental: eles podem concentrar recursos e esforços de campanha na corrida presidencial, amarrando a sorte eleitoral dos seus candidatos nas eleições para o Legislativo e para o Executivo estadual ao desempenho do candidato presidencial; ou, alternativamente, os partidos podem concentrar seus esforços nas disputas para governador, desenvolvendo estratégias nacionais e subnacionais pouco integradas entre si.

Procura-se demonstrar com essa perspectiva analítica a ausência de homogeneidade nas respostas dos partidos frente aos mesmos incentivos à nacionalização dados pela competição eleitoral pela Presidência. Em sistemas com múltiplos níveis de governo como o brasileiro, os partidos sem condição de apresentar candidatos presidenciais viáveis têm a opção de se especializar nas disputas estaduais. Quanto maior o impacto dos partidos nas eleições para governador sobre suas votações na eleição legislativa nacional, tanto maior a possibilidade de sucesso das estratégias de ampliação da base territorial de votação por meio do lançamento de candidaturas ao governo estadual nos vários distritos.

Apesar de ainda pouco estudada pela ciência política brasileira, a dimensão da nacionalização é de grande relevância para a atual agenda de pesquisa sobre os partidos políticos e sua atuação nas arenas eleitoral e governativa do presidencialismo de coalizão. Em sistemas partidários altamente nacionalizados, as agendas de política nacional tendem a ser determinantes para as carreiras parlamentares (Jones, 2010). Dada a vinculação entre a eleição presidencial e o desempenho eleitoral dos candidatos ao Legislativo, os parlamentares têm maiores incentivos para se alinhar aos interesses e agendas do presidente em detrimento de lideranças partidárias subnacionais.

O grau de nacionalização dos partidos afeta o custo da governabilidade no presidencialismo de coalizão (Raile et al., 2011) por dois outros motivos. Primeiro, porque partidos desnacionalizados costumam ser menos coesos e mais propensos a mobilizar os eleitores mediante políticas públicas desenhadas para atender interesses locais (Calvo e Leiras, 2012). Segundo, porque a desnacionalização do sistema partidário impacta positivamente na fragmentação. Independente da regra 
eleitoral utilizada, quanto maior a divergência entre os sistemas partidários nos planos distrital e nacional, tanto maior será a fragmentação total do sistema (Cox, 1999; Chhibber e Kollman, 2004).

O artigo analisa os dados relativos à evolução da nacionalização das eleições presidenciais, legislativas e para governador desde a primeira eleição direta para presidente em 1989. Esses indicadores são desagregados para os maiores partidos e comparados às estratégias eleitorais adotadas frente às disputas para o Executivo nacional e executivos estaduais. A nacionalização partidária foi operacionalizada por meio do índice de nacionalização partidária desenvolvido por Jones e Mainwaring (2003). A análise empírica se ampara ainda em um modelo de regressão linear misto para dados em painel dos estados brasileiros no período 1994-2010. O modelo estima os impactos médios do efeito coattails governatorial e presidencial sobre a votação dos maiores partidos.

\section{INSTITUIÇÕES E NACIONALIZAÇÃO DE SISTEMAS PARTIDÁRIOS NA POLÍTICA COMPARATIVA}

O conceito de nacionalização partidária tem sido utilizado na literatura comparativa para aferir o grau em que a variação da votação dos partidos entre os diferentes distritos se aproxima ou se distancia da votação nacional. Sistemas nacionalizados seriam aqueles em que a força eleitoral dos partidos se distribui homogeneamente entre os distritos. De forma análoga, um alto grau de regionalização se verificaria quando os partidos, em sua maioria, competem em poucos distritos ou concentram a sua votação em determinadas regiões ou estados do país (Jones e Mainwaring, 2003; Chhibber e Kollman, 2004; Brancati, 2008; Morgenstern et al., 2009). De modo mais geral, porém, a nacionalização se relaciona às formas predominantes de organização e mobilização eleitoral dos partidos. Quando o sistema partidário é nacionalizado, os partidos têm abrangência nacional e tendem a expressar-se e agir com uma orientação nacional comum em vez de se dividirem segundo questões regionais ou subnacionais (Jones, 2010).

Em sistemas com múltiplos níveis de governo, cabe incluir a dimensão vertical da nacionalização. A questão neste caso é saber se há congruência ou não entre os sistemas partidários formados nas distintas arenas eleitorais. Há integração vertical quando as arenas eleitorais no plano estadual ou provincial são conectadas à arena federal. Assim, é 
de se esperar que os sistemas partidários nacionais e subnacionais sejam bastante similares e que haja relativa correspondência entre os resultados das eleições para os distintos níveis de governo (Thorlakson, 2007; Leiras, 2010; Rodden e Wibbels, 2011; Schakel, 2013).

Sistemas plenamente nacionalizados são aqueles em que os partidos obtêm votações bastante similares em todos os distritos (nacionalização horizontal) e, além disso, as eleições nacionais condicionam os resultados das eleições em outros níveis de governo (integração vertical). Em tal situação, as eleições subnacionais possuem pouca independência frente aos alinhamentos e clivagens políticas nacionais. Isto implica dizer que as eleições subnacionais assumem o caráter de eleições de segunda ordem, nas quais o eleitor se manifesta basicamente com respeito ao governo nacional e suas propostas - por exemplo votando favoravelmente aos copartidários do chefe do Executivo no plano regional quando estão satisfeitos com o desempenho do governo e contrariamente quando insatisfeitos (Rodden e Wibbels, 2011).

As pesquisas que tratam do impacto do sistema presidencial sobre a competição partidária argumentam que a eleição direta do chefe do Executivo nacional tende a promover sistemas partidários mais nacionalizados (Shugart, 1995; Leiras, 2006; Hickens e Stoll, 2011). A eleição direta do Executivo nacional cria fortíssimos incentivos para a maximização de votos uma vez que esta transforma o país inteiro num distrito uninominal. Nenhum sistema parlamentarista adota uma cláusula de barreira tão elevada. Em poucas palavras, independente das regras eleitorais utilizadas, os partidos que lançam candidatos à Presidência precisam conquistar os votos de uma expressiva porção do eleitorado nacional se quiserem ser bem-sucedidos (Samuels, 2002:468). Disso decorre que a capacidade de obter votações difusas no território (i.e., mais nacionalizadas) representa uma vantagem competitiva na disputa à Presidência.

A influência da eleição presidencial sobre o sistema partidário depende em boa medida da força do chamado "efeito coattails" (efeito rabo de casaca), pelo qual o presidente atua como um "puxador de votos", beneficiando os candidatos do seu partido/coalizão ao Legislativo. Este efeito acontece basicamente por meio de dois mecanismos. Primeiro, a centralidade da eleição presidencial faz com que os candidatos ao Legislativo tenham incentivos para vincular sua campanha à campanha presidencial, com o intuito de se beneficiar das vantagens 
organizacionais, financeiras e da cobertura de mídia do seu candidato à Presidência (Samuels, 2002). Segundo, os eleitores muitas vezes se utilizam do partido do seu candidato presidencial preferido com um atalho informacional para ajudá-los a decidir o voto na eleição Legislativa (Golder, 2006; Samuels, 2002; Shugart, 1995).

As evidências reunidas por várias pesquisas indicam ainda que o efeito rabo de casaca será tanto mais forte quanto maior a proximidade temporal entre as eleições presidenciais e as eleições legislativas (Shugart e Carey, 1992; Jones, 1994; Golder, 2006; Hickens e Stoll, 2011). Além disso, quando o número de candidatos efetivos na eleição presidencial se aproxima de dois observam-se maiores incentivos para a coordenação de estratégias partidárias entre os diferentes distritos. Isto é, ainda que existam variações na força relativa dos candidatos à Presidência em cada distrito (por exemplo, alguns partidos ou coalizões podem ter maior penetração eleitoral em determinadas regiões do país), os partidos não devem ter muitos incentivos para apoiar terceiros candidatos quando a chance de vitória destes é reduzida. Assim, partidos e candidatos procurariam adotar uma estratégia comum em todos os distritos, alinhando-se a um dos dois blocos principais na disputa pela Presidência. Em conjunção com o efeito coattails, a coordenação de estratégias entre os distritos resultaria em um sistema mais nacionalizado (Hickens e Stoll, 2011).

Outro elemento-chave para entender a nacionalização ou regionalização partidárias diz respeito aos mecanismos de agregação partidária entre os distritos. Para que candidatos e partidos sejam capazes de comunicar uma orientação comum aos eleitores de diferentes distritos é preciso que haja uma coordenação de estratégias. A questão central é que a agregação partidária é mais difícil de se obter quando o voto é orientado por questões locais e os candidatos em um determinado distrito não precisam coordenar suas estratégias com candidatos nos demais. Para Chhibber e Kollman (2004), o grau de centralização do governo condiciona as preferências e estratégias de eleitores e candidatos, favorecendo maior ou menor nacionalização partidária. Em termos mais específicos, a centralização da autoridade governamental e perda de prerrogativas e poderes dos governos subnacionais induzem os eleitores a buscar, por meio do voto, influenciar nas decisões tomadas no nível nacional de governo. Da mesma forma, os candidatos terão incentivos para tomar posição sobre políticas públicas de escopo nacional decididas pelo governo central (Chhibber e Kollman, 
2004:74-78). De forma análoga, a descentralização teria como consequências o aumento de importância das eleições subnacionais e políticas públicas implementadas pelos governos estadual e local, propiciando estratégias partidárias regionalizadas (Thorlakson, 2007:73).

Igualmente importante é a vinculação entre as eleições subnacionais (governador) e as eleições legislativas nacionais. Em contextos nos quais os governos subnacionais possuem significativa autonomia política e fiscal, os partidos são descentralizados e seus diretórios regionais atuam de forma relativamente independente da organização nacional (especialmente na formação das listas partidárias e alianças eleitorais), deve-se observar o efeito rabo de casaca governatorial (gubernatorial coattails effect). Este efeito deve ser mais forte em sistemas políticos nos quais as eleições para deputado federal coincidem sempre ou quase sempre com as eleições para governador, porém não coincidem (ou o fazem apenas raramente) com as eleições para presidente (Jones, 1997; Samuels, 2003; Jones, 2010).

\section{UM MODELO DE COMPETIÇÃO PARTIDÁRIA EM SISTEMAS PRESIDENCIALISTAS MULTINÍVEL: ENTENDENDO AS ESTRATÉGIAS PARTIDÁRIAS}

Este artigo propõe um modelo tipológico simples que permite exatamente definir algumas expectativas teóricas com respeito aos mecanismos causais que conectam incentivos institucionais, estratégias partidárias e a variação da nacionalização dos partidos ao longo do tempo. Argumenta-se, em particular, que a análise subsistêmica da nacionalização partidária é essencial para entender uma questão ainda pouco pesquisada e teorizada, qual seja, a conexão entre as dimensões horizontal e vertical da nacionalização em sistemas federativos.

Antes de apresentar a tipologia, uma breve nota se faz necessária sobre a relação entre nacionalização partidária e crescimento eleitoral dos partidos. Não parece razoável supor que os partidos buscam a nacionalização das suas votações como um fim por si mesmo; este objetivo só faz sentido se permitir às organizações partidárias atender a outros fins como a maximizar votos, ocupar cargos no governo e influenciar as políticas públicas. Por princípio, quando os incentivos institucionais induzem os partidos a priorizar a maximização de votos (o que certamente se aplica à disputa presidencial), há também um incentivo para nacionalizar a votação. Partidos cuja capacidade de competição 
efetiva se limita a poucos distritos ou regiões de um país impõem, na prática, um teto ao seu próprio crescimento eleitoral. Ademais, organizações partidárias com votações territorialmente concentradas são mais vulneráveis a mudanças no perfil dos eleitorados locais ou ao crescimento de partidos adversários nos seus redutos. Em consonância com esta argumentação, as evidências comparativas reunidas por Jones e Mainwaring (2003) para os países das Américas demonstram que há forte correlação entre o grau de nacionalização e o tamanho dos partidos: partidos grandes são mais nacionalizados que partidos pequenos, via de regra.

O modelo supõe um regime presidencialista com múltiplos níveis de governo, no qual os partidos podem optar por concentrar recursos organizacionais e esforços de campanha na disputa pelo Executivo nacional ou pelos Executivos estaduais / provinciais. Em países presidencialistas federativos, vale notar, a capacidade de apresentar regularmente candidatos competitivos à Presidência e/ou a governador costuma ter grande impacto sobre a sobrevivência eleitoral e possibilidades de expansão territorial dos partidos, inclusive nas disputas para o Legislativo nacional (Shugart e Carey, 1992; Jones, 1997; Samuels, 2003; Hickens e Stoll, 2011; Magar, 2012). Dessa forma, pode-se supor que as estratégias adotadas pelos partidos nas disputas por cargos eletivos executivos afetam o escopo territorial da votação em outras eleições, incluindo a eleição para o Legislativo nacional, e em consequência, a nacionalização do sistema partidário.

A escolha entre priorizar a disputa por cargos em um destes dois níveis, por sua vez, depende de fatores como o grau de descentralização do governo, o qual afeta o valor relativo da Presidência no que se refere às governadorias. Fatores específicos aos partidos também influem na adoção de estratégias distintas. Entre estes, cabe destacar a capacidade das organizações partidárias de lançar ou não candidatos viáveis à Presidência.

Como já visto, uma vez que a eleição presidencial pode ter impacto expressivo sobre outras eleições (por exemplo, deputado federal, governador) através do efeito rabo de casaca e também em razão da necessidade de mobilizar um eleitorado nacional e coordenar os esforços do partido (ou coligação) entre os vários distritos, os partidos presidenciais têm fortes incentivos para "presidencializar" as suas estratégias eleitorais. Isto é, a disputa à Presidência induz os partidos a vincular as 
suas decisões de lançamento de candidaturas e realização de alianças eleitorais na disputa para o Legislativo nacional e também nas eleições estaduais, aos objetivos e estratégias dados pela candidatura presidencial. Em síntese, a presidencialização implica em estratégias eleitorais verticalizadas.

Se a adoção de uma estratégia de presidencialização faz sentido para os partidos que são competitivos na eleição presidencial, o mesmo não é necessariamente verdade para os partidos sem candidatos viáveis. Isto porque o lançamento de uma candidatura presidencial implica o gasto de recursos valiosos, que poderiam ser alocados de modo mais eficiente em disputas eleitorais onde o partido possui maiores chances de vitória (Melo, 2010).

Caberia, portanto, distinguir dois tipos de estratégia eleitoral. A presidencialização em sentido estrito é uma estratégia de competição eleitoral que subordina todas as demais estratégias do partido ao objetivo de conquistar a Presidência e/ ou participar do governo nacional. A presidencialização pode envolver tanto o lançamento de candidatura presidencial quanto o apoio a um dos candidatos presidenciais mais competitivos. Em virtude do caráter fortemente majoritário da disputa presidencial, o partido ou coalizão que deseja controlar o Executivo nacional tem incentivos para perseguir uma estratégia de nacionalização e expansão territorial da sua base de votação. No entanto, o mesmo não se aplica a um partido cuja participação na disputa presidencial tem como principal objetivo não a conquista da Presidência, mas sim a obtenção de benefícios indiretos em termos de votos em outras disputas, exposição na mídia nacional, entre outros ${ }^{1}$.

A segunda estratégia concerne uma situação virtualmente oposta à presidencialização, em que um partido com uma base eleitoral geograficamente concentrada disputa a Presidência com o objetivo primário de consolidar e manter a sua base regional. Esta estratégia, aqui denominada de presidencialização regional, é tipicamente adotada por partidos de expressão subnacional cuja votação se concentra em uma única região do país ${ }^{2}$. Seguindo Brancati (2008), definimos o termo região com respeito às regiões políticas de um país, isto é, às províncias ou estados que compõem a Federação. Vale notar que os dois tipos de presidencialização implicam a adoção de estratégias eleitorais verticalmente integradas, na medida em que os partidos subordinam a competição para todos os cargos de níveis inferiores de governo aos objetivos e 
constrangimentos dados pela disputa presidencial. No entanto, há uma diferença central no que tange ao seu escopo horizontal: a presidencialização sempre implica a obtenção de uma distribuição mais homogênea do voto entre as regiões, o que não ocorre no caso da presidencialização regional.

Em sistemas com múltiplos níveis de governo, outra alternativa que se coloca para os partidos pouco competitivos na arena presidencial é concentrar esforços nas eleições estaduais. Aqui trata-se de mobilizar os eleitores disputando eleições para governador e apresentar propostas e candidatos capazes de atender às demandas específicas dos eleitorados estaduais. Há basicamente dois tipos de provincialização. A estratégia de provincialização regional ou, simplesmente, provincialização, é uma estratégia de cunho defensivo e de escopo territorial restrito, que envolve a manutenção das bases eleitorais de um partido de expressão regional. Esta estratégia difere da presidencialização regional na medida em que o partido escolhe não participar da disputa nacional (presidencial) concentrando-se no objetivo de obter bom desempenho eleitoral na eleição para governador em um determinado estado da Federação. Por sua vez, a provincialização nacional caracteriza-se por combinar a priorização das disputas ao governo estadual e a busca pela expansão territorial do partido, por meio do lançamento de candidaturas competitivas a governador no maior número possível de estados. Quando bem-sucedida, esta estratégia pode viabilizar a eleição de expressivas bancadas na Câmara dos Deputados, desde que haja vinculação entre as eleições para governador e para deputado federal. Em tal contexto, ainda que a provincialização nacional implique baixa integração vertical das estratégias partidárias, a relativa nacionalização do partido nas eleições para governador deve resultar em nacionalização horizontal nas eleições para deputado federal. Ou seja, diferentemente da estratégia de presidencialização, a provincialização nacional envolve movimentos incongruentes nas dimensões da nacionalização horizontal e vertical.

Mesmo quando decidem participar da disputa presidencial, partidos orientados para a provincialização nacional adotam estratégias localistas, associando as candidaturas estaduais à presidencial nos estados em que for vantajoso, e evitando tal vinculação quando anteveem perdas eleitorais. O ponto a ressaltar é que a provincialização não é sinônimo de uma estratégia de não participação nas eleições presidenciais, 
ainda que alguns partidos possam decidir, em certos casos, abandonar a arena presidencial para se concentrar na disputa subnacional.

Por definição, as estratégias de provincialização e presidencialização são incongruentes entre si. Isto porque a presidencialização envolve a vinculação das estratégias eleitorais no plano estadual às estratégias nacionais. Esta vinculação implica custos e perda da autonomia dos diretórios estaduais do partido, pois estes últimos podem ser obrigados a não lançar candidaturas em determinados estados, apoiar um candidato presidencial pouco popular ou conhecido no estado, ou realizar alianças eleitoralmente desvantajosas para garantir a realização dos objetivos nacionais do partido. Quando a coordenação eleitoral é falha e os partidos adotam estratégias regionais incongruentes com a estratégia nacional, é menor a probabilidade dos seus candidatos se beneficiarem do desempenho eleitoral do cabeça de chapa na eleição presidencial (Hickens e Stoll, 2011) ${ }^{3}$. Estratégias de provincialização, mesmo quando envolvem a participação em eleições presidenciais, implicam a manutenção de uma organização altamente flexível e adaptável às circunstâncias locais, com o objetivo de maximizar a competitividade nas eleições estaduais.

A provincialização nacional é uma estratégia oposta à presidencialização regional, porque esta última estratégia implica alta integração vertical das estratégias eleitorais e baixa nacionalização horizontal. A presidencialização, por sua vez, se contrapõe frontalmente à provincialização: a primeira estratégia envolve movimentos no sentido da integração vertical das estratégias e da votação do partido, e nacionalização horizontal, enquanto a segunda se associa à baixa nacionalização horizontal e vertical. O Quadro 1 classifica cada uma das estratégias definidas nesta seção de acordo com o impacto esperado sobre as dimensões vertical e horizontal da nacionalização partidária.

\section{Quadro 1}

Uma Tipologia de Estratégias Eleitorais em Sistemas Presidenciais com Múltiplos Níveis de Governo

\begin{tabular}{|l|c|c|}
\hline \multirow{2}{*}{ Nacionalização Vertical } & \multicolumn{2}{|c|}{ Nacionalização Horizontal } \\
\hline Alta & Baixa & Alta \\
\hline Baixa & Presidencialização regional & Presidencialização \\
\hline
\end{tabular}

Fonte: Elaboração própria. 
Como se vê no quadro, a presidencialização é a única estratégia com potencial para nacionalizar os partidos nas dimensões vertical e horizontal. Por outro lado, o modelo tipológico sugere que a existência de cargos executivos abertos à disputa eleitoral em níveis inferiores de governo permite que partidos pouco competitivos na eleição presidencial não apenas sobrevivam eleitoralmente, mas que também nacionalizem (horizontalmente) a sua votação. Isso nos leva a crer que o ciclo eleitoral presidencial não necessariamente irá produzir um efeito de seleção natural no sistema político, favorecendo a sobrevivência de partidos e estratégias de orientação nacional, conforme as hipóteses consagradas sobre o efeito rabo de casaca. Pelo contrário, em sistemas com múltiplos níveis de governo os partidos políticos têm a seu dispor um leque maior de estratégias eleitorais capazes de garantir boas votações nacionais.

Nas seções seguintes, discorro sobre os incentivos institucionais e a evolução da nacionalização partidária agregada no Brasil. Em seguida, demonstro como as estratégias dos maiores partidos no período recente podem ser entendidas com base na tipologia acima.

\section{INSTITUIÇÕES POLÍTICAS E NACIONALIZAÇÃO PARTIDÁRIA NO BRASIL}

Diversas análises produzidas nas últimas duas décadas argumentam que o mix institucional brasileiro - separação de poderes, federalismo "robusto" e sistema eleitoral proporcional de lista aberta - contribui para a fragilidade institucional e baixa nacionalização dos partidos políticos. Conforme observado por Ames (2001:42), o sistema proporcional de lista aberta adotado no Brasil tende a enfraquecer a liderança nacional dos partidos vis-à-vis as lideranças estaduais. Isto porque os distritos eleitorais são os estados e a seleção dos candidatos é realizada pelos diretórios estaduais dos partidos. Outro aspecto é que o sistema de lista aberta fortalece os candidatos individuais em relação às lideranças partidárias, promovendo a personalização do processo eleitoral (Ames, 1995; Mainwaring, 1995, 1999). A relativa autonomia dos diretórios estaduais dos partidos para tomar decisões sobre as listas partidárias induz candidatos e eleitores a seguirem uma lógica localista. Para Samuels (2003), uma das implicações do caráter descentralizado dos partidos políticos seria a predominância do efeito rabo de casaca governatorial nas eleições para a Câmara Federal.

Em que pese o diagnóstico pessimista sobre a superposição entre federalismo e sistema eleitoral proporcional de lista aberta, a realização de 
eleições presidenciais e legislativas coincidentes a partir de 1994 vem contribuindo para aumentar a influência do pleito presidencial sobre a eleição para a Câmara. Contrariamente à tese de Samuels (2003), o trabalho de Soares (2013) demonstrou que o desempenho dos grandes partidos brasileiros nas eleições legislativas nacionais é afetado positivamente tanto pela votação dos seus candidatos a governador quanto pela votação dos seus candidatos à Presidência. Por sua vez, Pereira e Rennó (2007) encontraram evidências de que presidentes com boa performance nas urnas ajudam os deputados federais candidatos à reeleição que integram a coalizão governista na Câmara.

Não obstante o peso expressivo dos gastos subnacionais no total da despesa governamental, a federação brasileira experimentou leve processo de recentralização nas últimas décadas. Desde meados dos anos 1990, o Executivo federal vem ampliando suas capacidades de arrecadação de recursos e de formulação e coordenação de políticas públicas, como parte dos esforços de estabilização econômica e ajustamento fiscal. Medidas como a renegociação das dívidas dos estados, privatização de bancos estaduais e regras mais estritas de endividamento e gasto de pessoal introduzidas pela Lei de Responsabilidade Fiscal (LRF) contribuíram para reduzir a capacidade de gasto e financiamento de déficits dos governadores, revertendo parcialmente a descentralização fiscal dos anos 1980. A literatura sobre federalismo vem apontando, ainda, para a conformação de um padrão de produção de políticas sociais que se caracteriza pela municipalização da implementação e, por outro lado, manutenção do controle do governo central sobre a formulação e financiamento das políticas (Souza, 2002; Almeida, 2005; Afonso, 2006; Fenwick, 2009).

Em síntese, a relativa perda de importância das arenas decisórias estaduais, concomitantemente à mudança no calendário eleitoral e redução do número de candidatos efetivos à Presidência, implicam incentivos mais fortes para a nacionalização partidária. Por outro lado, o sistema eleitoral e a influência das eleições estaduais sobre as eleições legislativas nacionais apontam na direção contrária.

As pesquisas sobre nacionalização partidária no Brasil ganharam impulso nos últimos anos, com trabalhos que tentam compreender como a institucionalização da disputa presidencial nas últimas duas décadas vem contribuindo para organizar a competição eleitoral para os cargos mais importantes em torno de poucas coalizões partidárias viá- 
veis ${ }^{4}$. Nesta linha de análise, Cortez (2009) argumenta que a predominância do PT* e do PSDB no sistema partidário brasileiro reflete a capacidade destes dois partidos de nacionalizar as disputas estaduais, articulando estas últimas à disputa presidencial. Em outros termos, os dois principais competidores na eleição para o Executivo nacional utilizaram as eleições para governador como instrumento para a disputa eleitoral nacional. Como as disputas estaduais em grande parte dos distritos refletiram a bipolaridade nacional, tentativas de entrar no mercado eleitoral presidencial foram sistematicamente frustradas por falta de respaldo na maioria dos estados (ibidem:108-109).

Em trabalho mais recente, Limongi e Cortez (2010) demonstram como a vinculação cada vez maior entre a eleição presidencial e as eleições para governador torna improvável a sobrevivência de partidos sem uma estratégia de alianças nacional. Os autores argumentam que o PT e o PSDB e seus aliados preferenciais nas disputas à Presidência - PSB e DEM, respectivamente - vêm ampliando rapidamente a sua participação nas disputas nos estados. O único partido com a capacidade de se contrapor à polaridade PT-PSDB é o PMDB, cuja estratégia tem sido a de privilegiar as disputas para governador. Uma vez que a bipolaridade da disputa presidencial se reproduz nos estados, com um pequeno grupo de cinco partidos-PT, PSDB, PSB, DEM e PMDB - concentrando a maior parte dos votos ( $84 \%$ do total nacional em 2010), concluem os autores que há visível simplificação do quadro partidário, não obstante a fragmentação na disputa à Câmara dos Deputados.

Melo (2010) reforça o diagnóstico de Limongi e Cortez (2010), ao sugerir que a disputa presidencial vem contribuindo para a estruturação do sistema partidário nacional em torno de poucas coalizões partidárias. Em particular, as decisões tomadas pelos partidos com respeito ao lançamento de candidatos e alianças nas eleições para presidente, governador e deputado federal apresentam forte interdependência, constituindo uma estrutura de jogos aninhados (nested games). Considerando o caráter coalicional do presidencialismo brasileiro, a decisão de não lançar candidato à Presidência não implica necessariamente em abandonar a pretensão de participar do governo nacional. Os partidos podem adotar estratégias com o objetivo de ampliar o tamanho das suas bancadas na Câmara, e assim aumentar o seu potencial como possíveis parceiros da coalizão governativa. Neste sentido, na demo-

*Ver lista de siglas dos partidos políticos com os respectivos significados ao final do artigo. 
cracia brasileira os partidos políticos podem escolher entre priorizar as eleições presidenciais, as eleições para os governos estaduais ou as eleições para deputado federal.

A preponderância do PT e do PSDB nas disputas presidenciais teve como uma de suas consequências a rápida expansão e nacionalização das bases eleitorais destes dois partidos (Soares e Terron, 2008; Braga e Rodrigues-Silveira, 2011). Neste sentido, a competição pela Presidência no sistema político brasileiro estaria atuando na direção de contrabalançar os incentivos à regionalização dos partidos dados pelo sistema federativo.

Neste artigo, apresento um diagnóstico sobre os principais partidos brasileiros que converge com a posição da literatura brasileira recente sobre o papel estruturador da competição pela Presidência em um sistema partidário altamente fragmentado. A inovação trazida está na proposta de entender a diversidade de estratégias eleitorais dos partidos frente aos incentivos contraditórios dados pelo federalismo e pelo sistema presidencialista com respeito à nacionalização. Além disso, busca-se entender de forma sistemática como as disputas pelo Executivo estadual e nacional impactam as eleições legislativas nacionais e a nacionalização dos partidos. As análises aqui apresentadas também inovam com respeito às pesquisas anteriores, ao demonstrar que a relevância e a força do efeito "rabo de casaca" presidencial sobre a votação dos partidos na eleição para a Câmara variam de acordo com as estratégias eleitorais adotadas. Como último ponto, cumpre observar que a literatura brasileira tem dialogado pouco com a produção recente da ciência política comparativa sobre nacionalização partidária. Este artigo se propõe a preencher esta lacuna, situando o caso brasileiro frente ao debate internacional e apresentando indicadores comparativos de nacionalização partidária para o conjunto do sistema partidário e os principais partidos.

\section{EVOLUÇÃO DA NACIONALIZAÇÃO PARTIDÁRIA NO BRASIL PÓS-1990}

Esta seção apresenta evidências que comprovam uma tendência de ampliação moderada da nacionalização horizontal do sistema partidário brasileiro após 1994. Entre os vários indicadores de nacionalização partidária utilizados na literatura comparativa, optamos pela utilização do índice de nacionalização partidária (INP). O INP tem como vantagens a facilidade de cálculo e a comparabilidade entre distintos paí- 
ses e sistemas políticos (Jones e Mainwaring, 2003). O INP é calculado a partir do coeficiente Gini de distribuição de votos dos partidos no território, atribuindo pesos idênticos a cada um dos distritos eleitorais. Dada uma distribuição de votos perfeitamente equitativa, isto é, supondo que o partido obteve o mesmo percentual de votos em todos os distritos, o índice de Gini será igual a zero, indicando máxima nacionalização. Por outro lado, quanto mais heterogênea a distribuição de votos, tanto maior o Gini e, portanto, menor o grau de nacionalização horizontal. Assim, o INP é calculado como 1 menos o Gini de distribuição de votos, de modo que para um Gini de zero o INP assume valor máximo (1). O cálculo do índice de nacionalização do sistema partidário (INSP), que é uma medida agregada para o conjunto dos partidos, nada mais é que uma média do INP obtido para cada partido, ponderado pela sua votação.

Seguindo o mesmo procedimento adotado em outras pesquisas, o INSP foi calculado para a distribuição da votação dos partidos brasileiros nos 27 estados da Federação, cobrindo o período de 1989 a 2010. A análise inclui as eleições para presidente, governador e deputado federal. A Tabela 1 mostra a evolução da nacionalização partidária nas eleições para presidente e deputado federal a partir de 1989.

Tabela 1

INSP, Eleições Presidenciais e para Deputado Federal

(1989-2010)

\begin{tabular}{l|c|c}
\hline Ano & Presidente & Deputado Federal \\
\hline $1989 / 1990$ & 0,62 & 0,48 \\
1994 & 0,84 & 0,51 \\
1998 & 0,86 & 0,61 \\
2002 & 0,86 & 0,60 \\
2006 & 0,81 & 0,59 \\
2010 & 0,83 & 0,62 \\
\hline
\end{tabular}

Fonte: Elaboração própria, a partir dos dados do Ipea (http://ipeadata.gov.br) e do TSE (http://tse.gov.br).

A tabela mostra dois momentos de mudança nos índices de nacionalização partidária. Em 1994, a nacionalização da disputa presidencial se amplia mais de 20 pontos percentuais, mantendo-se desde então em patamares elevados, em torno de 0,80 . No que diz respeito à nacionalização da disputa legislativa, observa-se pequena ampliação em 1994, seguida de incremento expressivo em 1998. A partir de 2002, obser- 
va-se uma estabilização da nacionalização partidária, em patamares bem mais altos do que no início da série.

No que diz respeito à nacionalização da disputa presidencial ocorreu expressiva ampliação entre 1989 e 1998. Uma provável explicação para a evolução da nacionalização do sistema partidário presidencial está na diminuição do número de candidatos efetivos a partir de 1994. Desde aquele ano, a disputa vem adquirindo um caráter marcadamente bipolar, com a entrada ocasional de terceiros candidatos relevantes (a exemplo de Garotinho em 2002). O Gráfico 1 apresenta a evolução da fragmentação eleitoral das eleições presidenciais desde 1989:

Gráfico 1

Número Efetivo de Partidos, Eleições Presidenciais

(1989-2010)

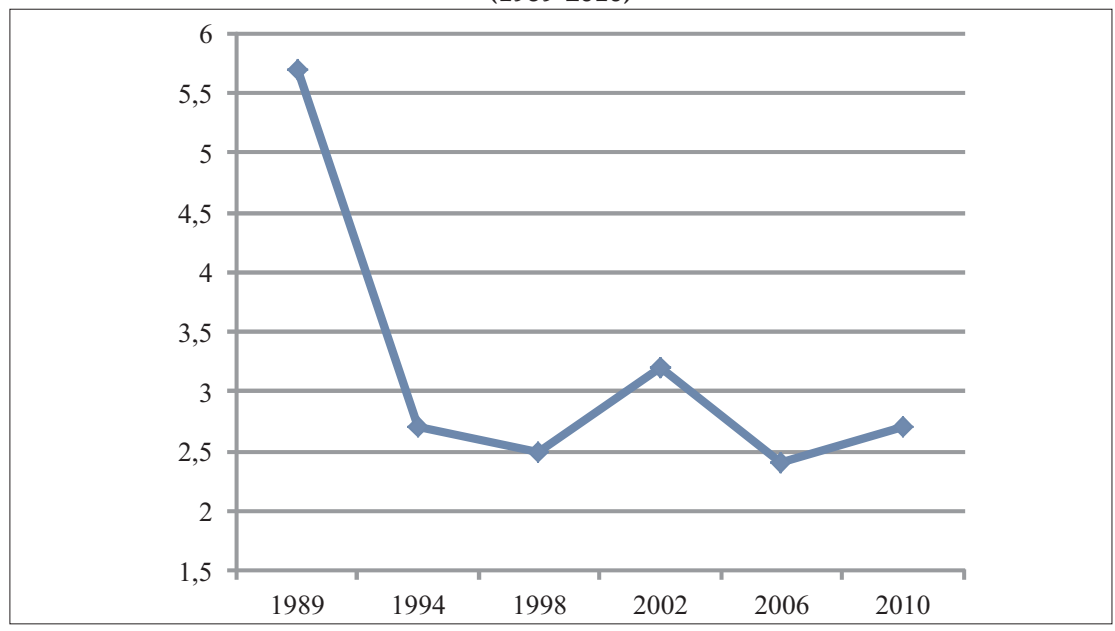

Fonte: Elaboração própria com base nos dados do TSE (http:/ / tse.gov.br).

\section{AS ESTRATÉGIAS DOS PARTIDOS BRASILEIROS FRENTE AOS INCENTIVOS INSTITUCIONAIS}

A análise realizada nesta seção inclui os partidos que obtiveram percentual mínimo de votos (4\%) nas três últimas eleições para a Câmara Federal (2002, 2006 e 2010). Com a aplicação dos critérios, foram selecionados oito partidos: PMDB, PSDB, DEM, PT, PSB, PP, PDT e PTB. Pelo menos desde 1998, estas oito legendas figuraram sempre entre as maiores em termos de votos para a Câmara Federal, concentrando um percentual da votação total que variou entre 73\% (2010) e 82\% (2002). 
Em resumo, são estes os partidos mais relevantes do ponto de vista eleitoral e sobre os quais concentramos nossa análise.

A Tabela 2 mostra a participação de cada um dos partidos selecionados nas eleições presidenciais realizadas desde 1989.

Tabela 2

Participação em Eleições Presidenciais, Partidos Selecionados

(1989-2010)

\begin{tabular}{l|c|c|c}
\hline Partido & Apresentou Candidato & Coligou-se a Outro Partido & Total \\
\hline PSDB & 6 & 0 & 6 \\
PT & 6 & 0 & 6 \\
PDT & 3 & 2 & 5 \\
PSB & 1 & 4 & 5 \\
PFL/DEM & 1 & 4 & 5 \\
PTB & 1 & 4 & 5 \\
PMDB & 2 & 2 & 4 \\
PP & 2 & 1 & 3 \\
\hline
\end{tabular}

Fonte: Elaboração própria com base nos dados do TSE (http:/ / tse.gov.br).

Conforme a Tabela 2, PT e PSDB são os únicos partidos a participar de todas as eleições presidenciais desde 1989 com candidato próprio. Quando se considera o total de participações (candidaturas + coligações), PMDB e PP são os partidos que menos estiveram presentes na disputa presidencial. Por sua vez, PSB e DEM se destacam no total de vezes em que apoiaram o PT e o PSDB respectivamente. Todas as participações em coligações destes dois partidos envolveram alinhamento a um dos principais competidores na disputa presidencial (quatro vezes). PTB e PDT vêm logo em seguida em número de apoios ao PSDB e ao PT: o PTB apoiou candidatos do primeiro partido em três ocasiões e o PDT apoiou os do PT em duas eleições. Por fim, o PMDB se aliou ao PSDB em 2002 e ao PT em 2010, enquanto o PP apoiou o PSDB em 1998.

Resta saber em que medida a decisão de se aliar a um dos dois principais partidos na arena presidencial implicou ou não a subordinação das estratégias na eleição estadual (governador) à estratégia nacional. No presidencialismo de coalizão brasileiro, a coordenação de estratégias entre diferentes partidos de uma mesma coligação envolve a troca de apoios e a postulação/retirada estratégica de candidaturas nos vários distritos. Assim, partidos que coordenam a sua estratégia com o partido do candidato presidencial ao qual concederam apoio devem 
apresentar, nas disputas a governador, baixo número de confrontos diretos com o cabeça de chapa da coligação nacional e elevado número de apoios ao cabeça de chapa nos estados em que este lançou candidato (Cortez, 2009).

Desenvolvi uma série de indicadores para avaliar em que medida os partidos aliados na corrida presidencial coordenam suas estratégias eleitorais no nível estadual. Para cada eleição, calculei o percentual de vezes em que: a) cada partido aliado apoiou o cabeça de chapa na eleição presidencial e vice-versa, na eleição para governador; b) o partido aliado e o cabeça de chapa competiram um contra o outro na eleição estadual $^{5}$. Em seguida, os percentuais de (a) e (b) foram subtraídos para obtenção de uma estatística resumo de coordenação eleitoral (um valor de 100 indicaria coordenação perfeita e-100 total incongruência das estratégias eleitorais). Considerei apenas as eleições realizadas a partir de 1994, por entender que os incentivos à coordenação eleitoral se tornaram mais fortes com a realização de eleições coincidentes (governador e presidente).

Tabela 3

Coordenação Eleitoral entre os Partidos Integrantes de Coligações Presidenciais nas Eleições para Governador, Partidos Selecionados

(1994-2010)

\begin{tabular}{l|c|c|c}
\hline $\begin{array}{l}\text { Partido Aliado } \\
\text { (cabeça de chapa) }\end{array}$ & $\begin{array}{c}\text { (A) Partidos Apoiaram } \\
\text { um ao Outro } \\
\text { (\%) }\end{array}$ & $\begin{array}{c}\text { (B) Partidos Competiram } \\
\text { um Contra o Outro } \\
\text { (\%) }\end{array}$ & (A)-(B) \\
\hline PSB (PT) & 62,85 & 13 & 49,9 \\
DEM (PSDB) & 59,20 & 14 & 44,9 \\
PDT (PPS/PT) & 44,21 & 15 & 29,2 \\
PTB (PPS/PSDB) & 42,11 & 22,5 & 19,6 \\
PP (PSDB) & 48,03 & 40 & 8,0 \\
PMDB (PSDB/PT) & 33,33 & 60 & $-26,7$ \\
\hline
\end{tabular}

Fonte: Cortez (2009); TSE (http:/ / tse.gov.br).

Como se vê na tabela, PSB e DEM são os partidos que mais coordenam as suas estratégias na disputa para governador com PT e PSDB respectivamente. Os aliados preferenciais do PT e do PSDB apoiam os cabeças de chapa presidenciais na maioria dos estados e, ainda, coordenam as decisões de lançamento de candidaturas de maneira a evitar confrontos diretos. Num outro extremo, encontra-se o PMDB como exemplo de baixa integração das alianças para presidente e governador. Nas 
poucas vezes em que participou de coligações presidenciais lideradas por PT (2010) ou PSDB (2002), o partido adotou estratégia independente nos estados, o que se reflete no elevado percentual de confrontos com estes. Finalmente, PTB e PP também apresentam índices de coordenação com os cabeças de chapa na eleição presidencial mais baixos relativamente ao PSB e DEM. O PDT é um caso intermediário. Apesar de também ter adotado estratégias orientadas para a disputa presidencial, o PDT apresenta menor consistência nas suas estratégias em relação aos parceiros preferenciais do PT e do PSDB. Com o rápido crescimento eleitoral de Luiz Inácio Lula da Silva e do PT nas primeiras eleições presidenciais após o retorno à democracia, no entanto, o PDT perdeu a capacidade de liderar a esquerda, assumindo papel de coadjuvante na disputa nacional (Melo, 2006). Desde então, o partido vem oscilando entre a tentativa de lançar candidaturas à Presidência e adotar postura de relativa independência com respeito ao PT (a exemplo da decisão de lançar Cristovam Buarque à Presidência em 2006), ou, alternativamente, se conformar com o alinhamento aos petistas nos estados, o que ocorreu de forma mais clara em 2010.

A Tabela 4 apresenta um índice de integração vertical de estratégias eleitorais. Primeiro calculei o número de vezes em que um partido presente na eleição presidencial, seja com candidato próprio, seja participando de coligação, apoiou um partido adversário na eleição para governador. Por partido adversário me refiro a todo e qualquer partido que participou de uma coligação presidencial adversária em cada eleição (exceção feita aos partidos e coligações com votação desprezí-

Tabela 4

Índice de Integração Vertical de Estratégias Eleitorais (0-100) por Partido (1994-2010)

\begin{tabular}{l|c}
\hline Partido & Integração Vertical \\
\hline PT & 92,16 \\
PSDB & 78,21 \\
PSB & 63,81 \\
DEM & 62,58 \\
PTB & 54,89 \\
PDT & 52,29 \\
PMDB & 36,97 \\
PP & 31,15 \\
\hline
\end{tabular}

Fonte: Elaboração própria com base nos dados do TSE (http:/ / tse.gov.br); Miranda (2013). 
vel, inferior a 5\% dos votos nacionais). A média deste primeiro índice foi subtraída de 100 e multiplicada pelo percentual de vezes em que o partido participou da eleição presidencial entre 1994 e $2010^{6}$.

PT e PSDB apresentam os escores mais elevados de integração vertical, $\mathrm{o}$ que é esperado considerando que estes são os dois partidos que vêm predominando nas eleições presidenciais. Como observa Cortez (2009), ainda que as alianças realizadas por PT e PSDB nos estados não sejam sempre ou necessariamente consistentes com a coligação nacional, os dois partidos estão quase sempre em lados opostos nas disputas a governador, o que demonstra capacidade de reproduzir no plano estadual a bipolaridade nacional. Na terceira e quarta posição no ranking de integração vertical, aparecem os aliados tradicionais de petistas e tucanos, PSB e DEM, respectivamente. Já o PP e o PMDB apresentam os escores mais baixos dentre todos os partidos analisados, com índices muito abaixo daqueles calculados para os partidos "presidencializados".

As evidências apresentadas até aqui indicam que PT, PSDB, DEM e PSB apresentam as estratégias eleitorais mais próximas à noção de presidencialização. Ou seja, em que pesem as variações ao longo do tempo, é possível dizer que estes partidos fizeram uma escolha no sentido de subordinar suas estratégias estaduais a uma estratégia nacional, cujo objetivo central é garantir a vitória na eleição presidencial e a participação no governo nacional. Quanto aos demais partidos aqui analisados - especialmente PMDB, PP e PTB - pode-se dizer que apresentam estratégias nacionais e estaduais bem menos consistentes com respeito aos casos de presidencialização. O que ainda resta saber é qual o papel das disputas estaduais para as estratégias de nacionalização e sobrevivência eleitoral destes partidos. Um primeiro indicador a ser considerado é a capacidade das agremiações partidárias de competir de forma efetiva pelas governadorias nos vários estados da Federação. A Tabela 5 traz um quantitativo simples de candidaturas a governador por partido e ano da eleição. Os três partidos com maior número de candidaturas a cada ano da série foram destacados em negrito.

A tabela mostra que os únicos partidos a figurar entre os três primeiros em número de candidaturas em todas as seis eleições consideradas são o PT e o PMDB. Quando se considera a média de candidaturas por ano, os quatro partidos mais presentes nas disputas estaduais são, pela ordem, PT, PMDB, PSDB e PDT. A maior presença nacional do PT e do PSDB é natural considerando o peso destas agremiações na disputa 
Tabela 5

Total de Candidaturas aos Governos Estaduais, Partidos Selecionados (1990-2010)

\begin{tabular}{l|c|c|c|c|c|c|c}
\hline Partido & $\mathbf{1 9 9 0}$ & $\mathbf{1 9 9 4}$ & $\mathbf{1 9 9 8}$ & $\mathbf{2 0 0 2}$ & $\mathbf{2 0 0 6}$ & $\mathbf{2 0 1 0}$ & Média \\
\hline PT & $\mathbf{2 3}$ & $\mathbf{1 9}$ & $\mathbf{1 6}$ & $\mathbf{2 4}$ & $\mathbf{1 8}$ & $\mathbf{1 0}$ & $\mathbf{1 8 , 3 3}$ \\
PSDB & $\mathbf{1 3}$ & 10 & $\mathbf{1 4}$ & 12 & $\mathbf{1 7}$ & $\mathbf{1 5}$ & $\mathbf{1 3 , 5 0}$ \\
PFL & 9 & 7 & 12 & 8 & 7 & 4 & 7,83 \\
PMDB & $\mathbf{1 6}$ & $\mathbf{1 3}$ & $\mathbf{1 6}$ & $\mathbf{1 6}$ & $\mathbf{1 9}$ & $\mathbf{1 9}$ & $\mathbf{1 6 , 5 0}$ \\
PSB & 1 & 4 & 7 & 19 & 8 & 9 & 8 \\
PDT & 10 & 14 & 6 & 9 & 11 & 4 & 9 \\
PTB & 5 & 5 & 2 & 8 & 1 & 3 & 4 \\
PP & 9 & 10 & 5 & 6 & 3 & 4 & 6,17 \\
\hline
\end{tabular}

Fonte: Elaboração própria com base nos dados do Ipea (http://ipeadata.gov.br ).

pelo Executivo nacional; a força estadual destes partidos é, em realidade, reflexo da sua preponderância nacional. Por sua vez, o PMDB se destaca pela manutenção da capacidade de apresentar candidaturas a governador em elevado número de estados, não obstante a sua perda de relevo no cenário nacional. O mesmo não se verifica no caso do PDT, partido que, a cada eleição, vem reduzindo o número de candidaturas.

O que se pode inferir dos dados é que o PMDB foi muito mais bemsucedido do que outros partidos na construção de uma estratégia de provincialização nacional. O que caracteriza esta estratégia é a baixa integração entre as decisões de formação de alianças e lançamento de candidaturas no plano nacional e estadual, bem como a apresentação de candidaturas a governador no maior número de distritos, com o objetivo de garantir a manutenção de uma base eleitoral bem distribuída no território brasileiro. Por sua vez, PP e PTB apresentam estratégias bem mais regionalizadas, o que se reflete no número decrescente de candidaturas ao longo dos anos.

Isso não quer dizer, no entanto, que se possa falar da adoção de estratégias de provincialização regional por esses partidos, uma vez que a realização de coligações permite às agremiações sem condições de lançar candidatos competitivos nas várias regiões ampliar a sua presença nacional. O grande número de coligações realizadas por todos os partidos eleitoralmente relevantes nas disputas a governador e a presença nacional dessas organizações na eleição para deputado federal indica claramente que não há, a rigor, partidos regionais dentre as maiores 
agremiações (Carreirão e Nascimento, 2010; Miranda, 2013). Por exemplo, nas eleições de 2010, PP e PTB lançaram quatro e três candidatos a governador respectivamente, porém em todos os demais estados estes partidos estiveram presentes como membros de coligações lideradas por outras agremiações.

\section{OS IMPACTOS DAS ESTRATÉGIAS PARTIDÁRIAS SOBRE A NACIONALIZAÇÃO NAS ELEIÇÕES LEGISLATIVAS}

Como as estratégias eleitorais até aqui descritas impactam na nacionalização dos partidos? Em particular, em que medida as eleições para governador e presidente influenciam a votação para deputado federal? Com base no argumento desenvolvido até aqui, pode-se supor que as estratégias de provincialização resultam em padrões de votação para a Câmara Federal mais associados à eleição estadual. De forma análoga, quando os partidos subordinam as suas estratégias estaduais às coligações presidenciais, é de se esperar que o efeito rabo de casaca presidencial ganhe relevo.

Para testar empiricamente a vinculação entre os pleitos, desenvolvi um modelo com dados longitudinais para as votações de cada um dos partidos para governador, deputado federal e presidente no período 1994-2010. Foram consideradas apenas as eleições em que os partidos participaram da eleição presidencial, seja como partido coligado, seja com candidato próprio. Nos casos em que o partido estava coligado, levou-se em conta a votação do partido do cabeça de chapa presidencial. Para lidar com as violações da regressão linear presentes na análise de dados longitudinais, adotou-se um modelo linear misto, com intercepto aleatório. Modelos de efeitos mistos estendem a regressão linear simples, incluindo termos para modelar a estrutura de correlação dos resíduos. A aplicação deste tipo de modelo à análise de dados longitudinais permite estimar efeitos aleatórios para cada uma das unidades de análise, além de efeitos fixos para as variáveis independentes $\mathrm{x}_{\mathrm{ij}}$ (Bagiella et al., 2000). A estimação de efeitos aleatórios no intercepto permite dar conta da heterogeneidade entre os casos decorrentes de fatores não mensurados (por exemplo, legados culturais ou históricos específicos ao estado $j$ ).

A variável dependente do modelo é a votação do partido $x$ no estado $j$ na eleição $i$ e as variáveis independentes de interesse são a votação para presidente (do partido ou cabeça de chapa no caso de partido coli- 
gado) e governador. Como controles, incluí uma dummy para a presença de um governador do partido no estado, no período anterior à eleição (incumbente), e uma medida do desvio da votação do partido na eleição para deputado federal relativa à votação nacional no pleito imediatamente anterior à i-ésima eleição (reduto $)^{7}$.

Os modelos foram estimados em separado para todos os partidos selecionados para análise. O modelo estimado para o PP apresentou problemas de colinearidade entre as variáveis reduto e votação para governador $(\mathrm{r}=0,7)$. Como o $\mathrm{N}$ é de apenas 54 , decidiu-se pela supressão da primeira variável. Os resultados são apresentados na Tabela 6.

Tabela 6

Modelo Linear Misto para Votação por Estado nas Eleições para Deputado Federal, Partidos Selecionados

(1990-2010)

\begin{tabular}{l|r|r|r|r|r|r|r|r}
\hline & PSDB & \multicolumn{1}{c|}{ PT } & \multicolumn{1}{c|}{ PFL } & PSB & PMDB & PDT & \multicolumn{1}{c}{ PTB } & \multicolumn{1}{c}{ PP } \\
\hline \multirow{2}{*}{ Constante } & $-33,87$ & $-67,10$ & $-41,77$ & 8,21 & $-52,12$ & $-23,88$ & $-14,76$ & 6,92 \\
& $(6,92)$ & $(5,44)$ & $(9,08)$ & $(9,09)$ & $(9,99)$ & $(7,90)$ & $(6,62)$ & $(1,59)$ \\
Reduto & $* * * 0,80$ & $* * * 1,49$ & $* * * 0,76$ & $-0,15$ & $* * * 1,13$ & $* * * 0,58$ & $* * * 0,38$ & - \\
& $(0,14)$ & $(0,11)$ & $(0,16)$ & $(0,19)$ & $(0,17)$ & $(0,16)$ & $(0,13)$ & - \\
Vt presidente & $* * * 0,10$ & $* * * 0,15$ & $* * * \mathbf{0 , 2 0}$ & $* 0,08$ & 0,03 & $-0,01$ & 0,00 & 0,09 \\
& $(0,03)$ & $(0,02)$ & $(0,05)$ & $(0,03)$ & $(0,03)$ & $(0,02)$ & $(0,02)$ & $(0,07)$ \\
Incumbente & 5,84 & 1,11 & 2,84 & $* * * 7,66$ & 1,70 & 1,43 & $* * * 19,16$ & $-2,78$ \\
& $(1,53)$ & $(1,16)$ & $(2,67)$ & $(1,73)$ & $(1,88)$ & $(1,79)$ & $(3,23)$ & $(2,60)$ \\
Vt governador & $* * * 0,08$ & $0,08^{* * *}$ & $* * * 0,20$ & 0,00 & $* * * \mathbf{0 , 1 0}$ & $* 0,05$ & $* * * \mathbf{0 , 1 1}$ & $* * * \mathbf{0 , 3 4}$ \\
& $(0,03)$ & $(0,02)$ & $(0,04)$ & $(0,03)$ & $(0,04)$ & $(0,02)$ & $(0,04)$ & $(0,05)$ \\
\hline N & 135 & 135 & 108 & 108 & 81 & 108 & 108 & $\mathbf{5 4}$ \\
Loglikelihood & $-430,48$ & $-364,67$ & $-369,544$ & $-319,75$ & $-276,99$ & $-305,68$ & $-312,20$ & $-179,139$ \\
\hline
\end{tabular}

Fonte: Elaboração própria com base nos dados do Ipea (http://ipeadata.gov.br) e do TSE (http://tse.gov.br).

Nota: ${ }^{* *} \mathrm{p}<0,001 ;{ }^{* *} \mathrm{p}<0,05 ;{ }^{*} \mathrm{p}<0,10$.

Os coeficientes em negrito indicam qual das duas variáveis de votação nas eleições majoritárias (presidente e governador) teve maior impacto sobre a votação do partido. Os resultados demonstram que o efeito rabo de casaca presidencial só é estatisticamente relevante para os partidos que adotaram estratégias de presidencialização, com a exceção do PDT. As equações estimadas para o PMDB, PP e PTB sugerem que o efeito da eleição presidencial é nulo, enquanto o rabo de casaca governatorial é positivo e estatisticamente significativo. Vale observar ainda que o efeito da votação de presidente é mais forte que o efeito da vota- 
ção de governador para três dos partidos "presidencializados": PT, PSB e PSDB. Os efeitos médios estimados para os coattails presidencial e governatorial com respeito à votação do DEM são similares.

De modo geral, a análise estatística suporta a argumentação desenvolvida até aqui. As estratégias adotadas pelos partidos com respeito às disputas para o Executivo nacional e estadual têm implicações claras sobre suas votações na eleição para a Câmara. Em poucas palavras, partidos que apostam na presidencialização tendem a depender mais ou de forma similar da votação na eleição presidencial para impulsionar seus candidatos ao Legislativo nacional comparativamente à votação para governador. Por sua vez, partidos que adotam estratégias de provincialização têm que contar basicamente com o efeito rabo de casaca dos seus candidatos a governador.

Resta saber como essa dinâmica impactou na nacionalização dos partidários no período em análise. O Gráfico 2 mostra a evolução do INP para os quatro maiores partidos brasileiros no período - PT, PSDB, PMDB e PFL/DEM.

O gráfico demonstra que a evolução da nacionalização acompanha, em alguma medida, os ciclos eleitorais presidenciais. O melhor resultado do PSDB e do DEM foi obtido em 1998, ano da reeleição do presidente

\section{Gráfico 2}

INP para Eleições Legislativas Nacionais, PT, DEM, PMDB e PSDB

(1990-2010)

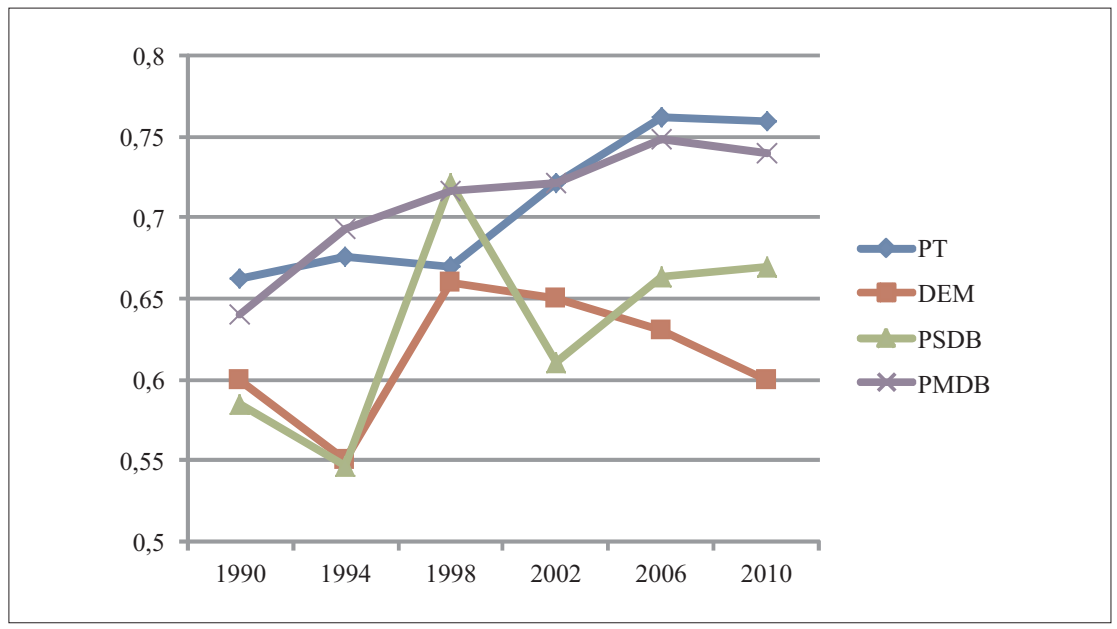

Fonte: Elaboração própria com base nos dados do Ipea (http:/ / www.ipeadata.gov.br). 
Fernando Henrique Cardoso, em que os dois partidos estiveram coligados na disputa presidencial. A partir de 2002, com uma série de vitórias do PT no pleito presidencial, o grau de nacionalização deste partido se amplia significativamente, enquanto PSDB e DEM perdem espaço. Por sua vez, a evolução da nacionalização do PMDB não parece indicar uma vinculação clara com a dinâmica eleitoral presidencial, dado que o INP se amplia em todos os anos, à exceção de 2010. Vale observar que, em 1998, o PMDB não apoiou nenhum candidato e em 2006 não celebrou coligação formal, decidindo apoiar informalmente a reeleição de Lula da Silva.

O Gráfico 3 compara a evolução do INP dos partidos médios (PP, PDT, PSB e PTB) no período. No interior deste grupo, o partido mais nacionalizado é o PP. Vale notar a rápida nacionalização do PSB, que passou de uma votação altamente regionalizada em $1990(\mathrm{INP}=0,25)$ para índices mais próximos da média nacional ao final da série (INP=0,55). Essa mudança no patamar de nacionalização se associa também ao impressionante crescimento eleitoral do PSB, que saiu de $2 \%$ dos votos em 1990 para 7,3\% em 2010. Em contraste, o PDT teve a sua votação reduzida à metade, de 10\% em 1990 para 5\% do total de votos válidos em 2010.

\section{Gráfico 3}

INP para Eleições Legislativas Nacionais, PP, PDT, PSB e PTB

(1990-2010)

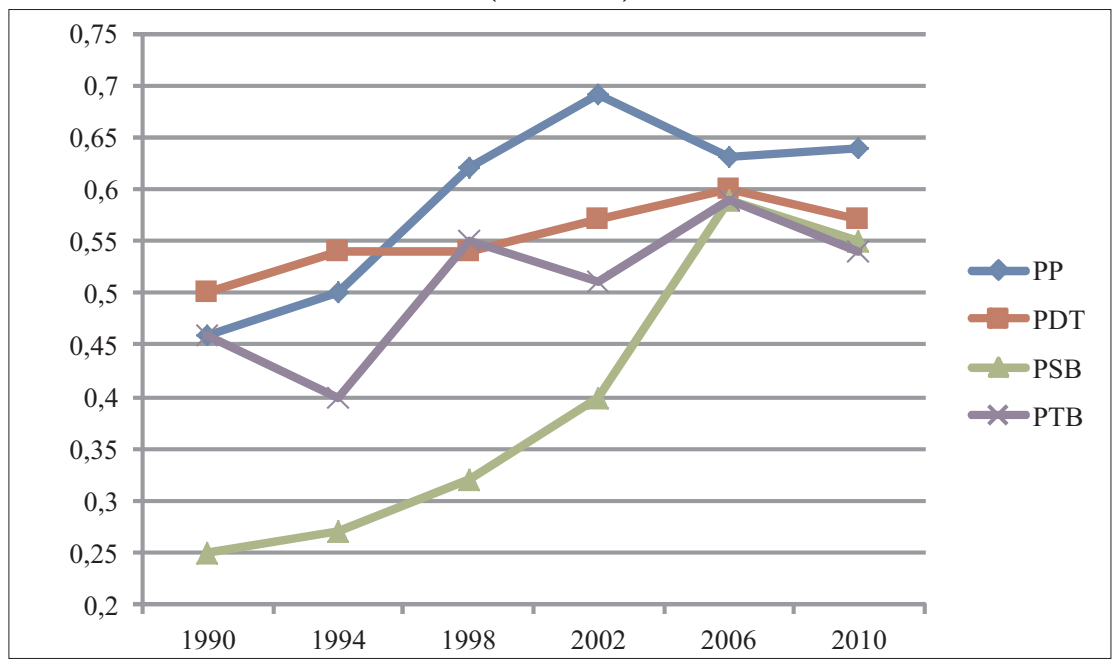

Fonte: Elaboração própria com base nos dados do Ipea (http:/ / www.ipeadata.gov.br). 
É interessante observar que, à exceção do DEM, que manteve o mesmo índice de nacionalização observado no início da série, todos os demais partidos aqui analisados experimentaram crescimento da nacionalização eleitoral entre 1990 e 2010. Entretanto, uma simples análise de variância utilizando o INP como variável dependente demonstra que a variação entre os partidos é muito maior do que a variação entre os anos. A estatística F para a comparação entre os resíduos do modelo apenas com a variável partidos e o modelo completo (ano de eleição + partidos) é de 9,27 ( $p<0,001)$, o que comprova que as diferenças entre os partidos "explicam" muito mais da variação no INP do que as mudanças agregadas no INP ano a ano. Chama a atenção ainda o fato de que os dois partidos que lograram alcançar os mais elevados níveis de nacionalização ao longo destes 20 anos - PT e PMDB - se valeram de estratégias rigorosamente incongruentes entre si. Enquanto o PT apostou de forma decidida na presidencialização, subordinando todas as estratégias do partido ao objetivo de conquistar a Presidência, o PMDB escolheu o caminho da provincialização nacional, apostando no lançamento de candidaturas competitivas no maior número de estados, independente dos posicionamentos nacionais do partido.

O desempenho do PP nas eleições legislativas nacionais fornece evidências adicionais com respeito aos incentivos institucionais contraditórios dados pela combinação entre federalismo e presidencialismo. A decisão de não se vincular a nenhum dos blocos partidários capitaneados por PT e PSDB na eleição presidencial - exceção feita à eleição de 1998, quando apoiou a reeleição de Fernando Henrique - permitiu ao partido sobreviver eleitoralmente apostando no pragmatismo na arena eleitoral e governativa. Enquanto o PP manteve sua parcela do voto nacional em torno de $7 \%-8 \%$, seu mais importante competidor no campo da direita, o DEM, experimentou profundas perdas eleitorais a partir de 2002, reduzindo sua votação em 10 pontos percentuais entre 1998 e 2010. Na condição de parceiro menor do PSDB, este último partido manteve-se fiel à estratégia de presidencialização, juntando-se ao bloco de oposição ao governo com as vitórias do PT nas eleições presidenciais em 2002, 2006 e 2010. Sem as amarras de uma estratégia nacional, de forma diversa, o PP evitou perdas que incorreriam se tivesse optado por se contrapor a um governo de centro-esquerda popular; pelo contrário, o partido apoiou o governo Lula da Silva no Legislativo, sendo devidamente recompensado por isso com pastas ministeriais. É ainda digno de nota o expressivo crescimento da nacionalização eleitoral do PP no período, da ordem de 39\% (segundo maior 
dentre todos os casos, logo atrás do PSB), considerando ter sido este o partido com o menor número de participações em eleições presidenciais no período.

\section{CONSIDERAÇÕES FINAIS}

Em consonância com as hipóteses da literatura comparativa, a evolução recente da nacionalização partidária no caso brasileiro demonstra que a formação do sistema partidário se vincula à disputa pela Presidência da República. A realização de eleições coincidentes para presidente, governador e deputado federal desde 1994 vem contribuindo para ampliar os incentivos à coordenação entre as disputas, assim impulsionando a nacionalização das eleições para a Câmara.

Se é verdade que a institucionalização da disputa presidencial contribui para conferir estrutura e inteligibilidade a um sistema partidário que figura entre os mais fragmentados do mundo, é também verdade que as instituições federativas e o caráter coalicional do presidencialismo brasileiro possibilitam a sobrevivência de partidos que adotam estratégias nacionais e estaduais fracamente integradas. Note-se ainda que a possibilidade de participar de coligações em apoio a candidaturas presidenciais, obtendo compensações dos cabeças de chapa na disputa ao Executivo estadual (na forma de retirada de candidaturas destes últimos em alguns estados, por exemplo), também favorece a sobrevivência de partidos provincializados, dado que as instituições eleitorais e partidárias brasileiras garantem suficiente flexibilidade para viabilizar a realização de alianças adaptadas às realidades locais. Assim, um dos efeitos do leque de opções abertas aos partidos sem condições de lançar candidatos viáveis à Presidência é a mitigação do efeito de seleção natural da competição presidencial. O não alinhamento aos grandes partidos presidenciais não resulta necessariamente em perdas eleitorais ou em padrões de votação mais desnacionalizados. De fato, PMDB e PP figuravam em 2010 no grupo dos cinco maiores partidos nacionais, tendo o PMDB obtido a segunda maior votação nacional e o PP a quinta, logo atrás do DEM; estes dois partidos também integravam o grupo dos quatro mais nacionalizados, estando o PP na quarta posição e o PMDB na segunda.

Somam-se a estes efeitos os custos potenciais de estratégias de presidencialização em um sistema político no qual os benefícios de ocupar cargos e participar do governo federal são muito expressivos relativa- 
mente aos benefícios de policy de permanecer na oposição. O declínio eleitoral do DEM reflete precisamente o custo de fazer oposição a um governo adversário nas urnas, mantendo uma estratégia eleitoral consistente, frente ao pragmatismo de outras organizações de direita, como o PP.

O artigo traz algumas contribuições importantes à literatura brasileira e comparativa. Primeiro, aponta para uma limitação das tradicionais análises agregadas da nacionalização partidária, demonstrando a ausência de homogeneidade nas estratégias de nacionalização dos partidos em um sistema federativo. Em segundo lugar, a análise empírica sugere um diagnóstico que diverge de análises anteriores sobre o grau de integração entre as eleições presidenciais e legislativas nacionais. Ao contrário de um sistema "federalizado", no qual o efeito rabo de casaca presidencial é praticamente anulado pela força dos governadores, como sugere Samuels (2003), o que se observa é uma divisão dos grandes partidos em dois grupos. Um de partidos "provincializados", que dependem da votação dos seus candidatos a governador para impulsionar a eleição de bancadas na Câmara Federal, e um grupo "presidencializado" no qual o efeito rabo de casaca presidencial é determinante. Em terceiro lugar, o artigo qualifica e complementa as análises de Limongi e Cortez (2010) e Cortez (2009) sobre a nacionalização vertical do sistema partidário. Diferentemente do cenário apontado por esses autores, de estabilização da competição eleitoral no plano subnacional em paralelo à crescente verticalização das estratégias partidárias, a análise teórica e empírica aqui apresentada sugere que o sistema político brasileiro é suficientemente flexível para acomodar estratégias de não alinhamento aos principais partidos presidenciais.

No que diz respeito a este último aspecto, o artigo aponta novos caminhos para se entender a formação de coalizões no presidencialismo brasileiro. Estudos comparados recentes demonstram que a formação de coligações ou coalizões pré-eleitorais amplia consideravelmente as chances dos partidos formarem uma coalizão de governo no período pós-eleição (Albala, 2014; Chasquetti, 2001). Entretanto, ainda que isso seja verdade também para o caso brasileiro, os incentivos para a participação em coalizões pré e pós-eleitorais não são os mesmos para todos os partidos. As evidências apresentadas neste artigo indicam que partidos presidencializados, como PSB e DEM, obtêm claros benefícios eleitorais associando-se aos candidatos presidenciais de PT e PSDB, 
respectivamente. Por sua vez, mesmo quando participam da eleição presidencial, PMDB, PDT, PP e PTB não parecem obter tais benefícios. Presumivelmente, estes últimos partidos teriam maiores incentivos para exigir do candidato eleito "pagamentos adicionais" por seu apoio eleitoral na forma de cargos, recursos de pork e financiamento de campanha, hipótese que mereceria ser testada em futuros estudos.

Talvez não coincidentemente, os três partidos que escolheram estratégias mais próximas à definição de provincialização - PMDB, PP e PTB adotaram postura office-seeking frente às vitórias do PT nas três últimas eleições presidenciais. A partir de dados de survey realizado entre os parlamentares, Melo e Câmara (2012) identificam no interior do legislativo brasileiro um bloco de partidos de sustentação, integrado por estas três organizações. Do ponto de vista ideológico, PMDB, PP e PTB mostram-se mais semelhantes ao DEM e ao PSDB do que ao PT, o que demonstra que a participação nos gabinetes formados por Lula da Silva e Dilma Rousseff entre 2003 e 2014 implicou sacrifício dos objetivos de policy em favor da ocupação de cargos no governo. Em outras palavras, estratégias de provincialização nacional na arena eleitoral são plenamente congruentes com (além de funcionais à reprodução de) estratégias office-seeking na arena governativa. De fato, para partidos pouco coesos, com baixa capacidade de coordenação centralizada, e/ ou ideologicamente distantes do candidato à Presidência, as possibilidades de obter ganhos de policy e votos apoiando o candidato de outro partido na corrida à Presidência são naturalmente limitadas. Assim, conclui-se que a melhor estratégia para organizações como o PMDB é garantir acesso aos cargos e verbas do governo federal, sem, no entanto, sacrificar totalmente a capacidade das seções estaduais do partido de definir estratégias regionalizadas de formação de coligações e lançamento de candidaturas.

À guisa de conclusão, pode-se afirmar que o caráter coalicional do presidencialismo brasileiro e sua superposição a um sistema federativo resultam em incentivos contraditórios com respeito à nacionalização partidária. A ampliação moderada da nacionalização horizontal a partir de 1994 oculta um sistema segmentado, no interior do qual alguns partidos se nacionalizam por meio de estratégias eleitorais altamente verticalizadas, a exemplo do PT, enquanto outros logram obter distribuições de votação mais homogêneas por meio de estratégias nacionais e estaduais incongruentes entre si, a exemplo do PP e do PMDB. 
Presumivelmente, este mix institucional, em combinação com um sistema eleitoral permissivo, ajuda a manter em níveis elevados a fragmentação partidária na Câmara dos Deputados, não obstante a redução do número efetivo de candidatos à Presidência.

(Recebido para publicação em abril de 2014)

(Reapresentado em outubro de 2014)

(Aprovado para publicação em fevereiro de 2015) 


\section{NOTAS}

1. Em sistemas que utilizam eleição em dois turnos para a escolha do presidente, os partidos possuem maiores incentivos e oportunidades para lançar candidatos independentemente da sua chance de vitória (i.e., um partido pode lançar um candidato com o objetivo de aumentar seu poder de barganha frente a um dos primeiros colocados em um hipotético segundo turno).

2. No Brasil não se observa este tipo de presidencialização, porque a legislação eleitoral restringe as possibilidades de organização e sobrevivência de partidos regionais, diferentemente de federações como o Canadá ou a Argentina. Um exemplo claro desta estratégia seria a atuação do partido Compromiso Federal (CF) nas eleições presidenciais argentinas. Liderado pela família Rodríguez Saa, da província de San Luís, o partido vem apresentando candidatos à Presidência desde 2003, sempre com votações territorialmente concentradas em San Luís.

3. É importante ressaltar que o problema da coordenação entre as estratégias nacionais e estaduais dos partidos não é específica a disputas envolvendo coligações. Sobre isso, ver a análise de Leiras (2006) com relação às dificuldades de coordenação no interior dos partidos Peronista e Radical no período recente.

4. Vale notar, porém, que essa agenda de pesquisa não é nova, e já estava presente em trabalhos como os de Lima Jr. (1983) e Santos (2003), que utilizaram a perspectiva da nacionalização para analisar a ascensão e queda do sistema partidário da República de 1946-1964.

5. Para cálculo do percentual de apoios, utilizei como denominador o total de candidaturas a governador do PT ou PSDB a cada eleição. Isso porque, uma vez que os partidos considerados na análise participam das disputas estaduais em todos ou quase todos os estados (como coligados ou cabeças de chapa), a decisão de não apoiar o PT ou PSDB em algum estado indica quase sempre que o partido apoiou outra candidatura ou lançou candidatura própria. No caso do percentual de confrontos, considerou-se também o total de candidaturas do cabeça de chapa presidencial.

6. A ponderação do índice pelo número de participações na eleição presidencial é necessária, porque partidos que permanecem neutros na disputa nacional devem enfrentar, ceteris paribus, menores constrangimentos nas decisões relativas às alianças nos estados. Neste sentido, a decisão de não participar da corrida à Presidência já indica, por si só, preferência por uma estratégia de não verticalização. Hipoteticamente, uma estratégia perfeitamente integrada implicaria participar de todas as eleições presidenciais e nunca apoiar um partido adversário na eleição para governador.

7. A variável reduto foi calculada subtraindo-se da votação do partido no estado na eleição anterior o percentual da votação nacional, somando 100 e dividindo o resultado por 2. Com essa transformação matemática, votações acima da média nacional assumem valores maiores que 50 e valores abaixo da média, inferiores a 50. 


\section{REFERÊNCIAS BIBLIOGRÁFICAS}

ALBALA, Adrian. (2014), The Timing Effect of Presidentialism on Coalition Governments: Evidence from Latin America. Trabalho apresentado no XXIII Congresso Mundial da IPSA, Montreal, CA, 19-24 de julho.

AFONSO, José Roberto. (2006), Novos Desafios à Descentralização Fiscal no Brasil. Trabalho apresentado no Seminário Regional de Política Fiscal, Santiago, Chile, 23-26 de janeiro.

ALMEIDA, Maria Hermínia Tavares. (2005), "Recentralizando a Federação?". Revista de Sociologia e Política, no 24, pp. 29-40.

AMES, Barry. (1995), "Electoral Rules, Constituency Pressures, and Pork Barrel: Bases of Voting in the Brazilian Congress". Journal of Politics, vol. 57, no 2, pp. 324-343.

__.. (2001), The Deadlock of Democracy in Brazil. Ann Arbor, The University of Michigan Press.

BAGIELLA, Emilia et al. (2000), “Mixed Effects Models in Psychophysiology”. Psychophysiology, vol. 37, no 1, pp. 13-20.

BRAGA, Maria do Socorro; RODRIGUES-SILVEIRA, Rodrigo. (2011), Competição Partidária e Territorialidade (2 r) do Voto: Mudanças na Distribuição do Padrão Espacial do Voto para Presidente da República do Brasil. Trabalho apresentado no XXXV Encontro Anual da Anpocs, Caxambu, MG, 24-28 de outubro.

BRANCATI, Dawn. (2008), "The Origins and Strengths of Regional Parties". British Journal of Political Science, vol. 38, no 1, pp. 135-159.

CALVO, Ernesto; LEIRAS, Marcelo. (2012), “The Nationalization of Legislative Collaboration: Territory, Partisanship, and Policymaking in Argentina". Revista Ibero-Americana de Estudos Legislativos, vol. 2, no 1, pp. 2-19.

CARREIRÃO, Yan Souza; NASCIMENTO, Fernanda P. (2010), “As Coligações nas Eleições para os Cargos de Governador, Senador, Deputado Federal e Deputado Estadual no Brasil (1986/2006)". Revista Brasileira de Ciência Política, no 4, pp. 75-104.

CHASQUETTI, Daniel. (2001), “Democracia, Multipartidismo y Coaliciones en América Latina: Evaluando la Difícil Combinación", in J. Lanzaro (ed.), Tipos de Presidencialismos y Coaliciones Políticas en América Latina. Buenos Aires, Clacso, pp. 319-357.

CHHIBBER, Pradeep K.; KOLLMAN, Ken. (2004), The Formation of National Party Systems Federalism and Party Competition in Canada, Great Britain, India, and the United States. Princeton, NJ, Princeton University Press.

CORTEZ, Rafael. (2009), Eleições Majoritárias e Entrada Estratégica no Sistema Partidário-eleitoral Brasileiro. Tese (Doutorado em Ciência Política), Universidade de São Paulo, São Paulo.

COX, Gary. (1999), "Electoral Rules and Electoral Coordination". Annual Review of Political Science, vol. 2, pp. 145-161.

FENWICK, Tracy Beck. (2009), "Avoiding Governors: The Success of Bolsa Família”. Latin American Research Review, vol. 44, no 1, pp. 102-131. 
GOLDER, Matt. (2006), "Presidential Coattails and Legislative Fragmentation". American Journal of Political Science, vol. 50, no 1, pp. 34-48.

HICKENS, Allen; STOLL, Heather. (2011), "Presidents and Parties: How Presidential Elections Shape Coordination in Legislative Elections". Comparative Political Studies, vol. 44, no 7, pp. 854-883.

JONES, Mark. (1994), "Presidential Election Laws and Multipartism in Latin America". Political Research Quarterly, vol. 47, no 1, pp. 41-57.

. (1997), "Federalism and the Number of Parties in Argentine Congressional Elections". The Journal of Politics, vol. 59, no 2, pp. 538-549.

. (2010), "Beyond the Electoral Connection: The Effect of Political Parties on the Policymaking Process", in C. Scartascini, E. Stein e E. Tommasi (eds.), How Democracy Works: Institutions, Actors, and Arenas in Latin American Policymaking. Washington D.C., Inter-American Development Bank/David Rockfeller Center for Latin American Studies, pp. 19-46.

; MAINWARING, Scott. (2003), “The Nationalization of Parties and Party Systems: An Empirical Measure and an Application to the Americas". Party Politics, vol. 9, no 2, pp. 139-166.

LEIRAS, Marcelo. (2006), Parties, Provinces and Electoral Coordination: A Study on the Determinants of Party and Party System Aggregation in Argentina, 1983-2005. Tese (Doutorado em Ciência Política), University of Notre Dame, Indiana.

. (2010), “Los Procesos de Descentralización y la Nacionalización de los Sistemas de Partidos en América Latina". Política y Gobierno, vol. 17, no 2, pp. 205-241.

LIMAJÚNIOR, Olavo Brasil de. (1983), Os Partidos Políticos Brasileiros: A Experiência Federal e Regional, 1945-1964. Rio de Janeiro, Graal.

LIMONGI, Fernando; CORTEZ, Rafael. (2010), “As Eleições de 2010 e o Quadro Partidário". Novos Estudos CEBRAP, no 88, pp. 21-37.

MAGAR, Eric. (2012), "Gubernatorial Coattails in Mexican Congressional Elections". The Journal of Politics, vol. 74, no 2, pp. 383-399.

MAINWARING, Scott. (1995), "Brazil: Weak Parties, Feckless Democracy", in S. Mainwaring e T. Scully (eds.), Building Democratic Institutions: Party Systems in Latin America. Stanford, Stanford University Press.

. (1999), Rethinking Party Systems in the Third Wave of Democratization: The Case of Brazil. Stanford, Stanford University Press.

MELO, Carlos Ranulfo de. (2006), “Sistema Partidário, Presidencialismo e Reforma Política no Brasil", in G. A. D. Soares; L. Rennó (eds.), Reforma Política: Lições da História Recente. Rio de Janeiro, FGV Editora.

. (2010), "Eleições Presidenciais, Jogos Aninhados e Sistema Partidário no Brasil”. Revista Brasileira de Ciência Política, no 4, pp. 13-41.

; CÂMARA, Rafael. (2012), “Estrutura da Competição pela Presidência e Consolidação do Sistema Partidário no Brasil". DADOS - Revista de Ciências Sociais, vol. 55, no 1, pp. 71-117. 


\section{Nacionalização Partidária e Estratégias Eleitorais no Presidencialismo de Coalizão}

MIRANDA, Geralda Luiza de. (2013), "Coligações Eleitorais: Tendências e Racionalidades nas Eleições Federais e Majoritárias". Revista de Sociologia e Política, vol. 21, oㅡ 47, pp. 69-90.

MORGENSTERN, Scott et al. (2009), "Party Nationalization and Institutions". The Journal of Politics, vol. 71, no 4, pp. 1322-1341.

PEREIRA, Carlos; RENNÓ, Lúcio. (2007), “O que é que o Reeleito Tem? O Retorno: O Esboço de uma Teoria da Reeleição no Brasil". Revista de Economia Política, vol. 27, no 4 (108), pp. 664-683.

RAILE, Eric D. et al. (2011), "The Executive Toolbox: Building Legislative Support in a Multiparty Presidential Regime". Political Research Quarterly, vol. 64, no 2, pp. 323-334.

RODDEN, Jonathan; WIBBELS, Erik. (2011), “Dual Accountability and the Nationalization of Party Competition: Evidence from Four Federations". Party Politics, vol. 17, no 5, pp. 629-653.

SAMUELS, David. (2002), "Presidentialized Parties: The Separation of Powers and Party Organization and Behavior". Comparative Political Studies, vol. 35, no 4, pp. 461-483.

. (2003), Ambition, Federalism, and Legislative Politics in Brazil. Cambridge, Cambridge University Press.

SANTOS, Wanderley Guilherme dos. (2003), O Cálculo do Conflito: Estabilidade e Crise na Política Brasileira. Belo Horizonte, Editora UFMG.

SCHAKEL, Arjan H. (2013), “Nationalisation of Multilevel Party Systems: A Conceptual and Empirical Analysis". European Journal of Political Research, vol. 52, no 2, pp. $212-236$

SHUGART, Matthew. (1995), "The Electoral Cycle and Institutional Sources of Divided Government". American Political Science Review, vol. 89, № 2, pp. 327-343.

;CAREY, John M. (1992), Presidents and Assemblies: Constitutional Design and Electoral Dynamics. Cambridge, UK, Cambridge University Press.

SOARES, Gláucio Ary Dillon; TERRON, Sonia. (2008), “Dois Lulas: A Geografia Eleitoral da Reeleição (Explorando Conceitos, Métodos e Técnicas de Análise Geoespacial)". Opinião Pública, vol. 14, no 2, pp. 269-301.

SOARES, Márcia Miranda. (2013), “Influência Majoritária em Eleições Proporcionais: Os Efeitos Presidenciais e Governatoriais sobre as Eleições para a Câmara dos Deputados Brasileira (1994-2010)". DADOS - Revista de Ciências Sociais, vol. 56, no 2, pp. 413-437.

SOUZA, Celina. (2002), "The Prospects of a Center-Constraining Federation in a Fragmented Polity". Publius: The Journal of Federalism, vol. 32, № 2, pp. 23-48.

THORLAKSON, Lori. (2007), “An Institutional Explanation of Party System Congruence: Evidence from Six Federations". European Journal of Political Research, vol. 46, no 1, pp. 69-95. 
André Borges

Lista de Siglas dos Partidos Políticos

DEM - Democratas

PDT - Partido Democrático Trabalhista

PFL - Partido da Frente Liberal

PMDB - Partido do Movimento Democrático Brasileiro

PP - Partido Progressista

PPS - Partido Popular Socialista

PSB - Partido Socialista Brasileiro

PSDB - Partido da Social Democracia Brasileira

PT - Partido dos Trabalhadores

PTB - Partido Trabalhista Brasileiro 


\section{RESUMO}

Nacionalização Partidária e Estratégias Eleitorais no Presidencialismo de Coalizão

Este artigo explora o papel das eleições presidenciais e do federalismo sobre a nacionalização dos partidos no presidencialismo de coalizão brasileiro. Argumenta-se que a resposta estratégica dos partidos frente aos incentivos nacionalizantes da eleição presidencial tende a variar de forma significativa em sistemas multinível, especialmente na presença de um efeito "rabo de casaca" governatorial. Enquanto alguns partidos obtêm sucesso em mobilizar um eleitorado nacional por meio da "presidencialização", outras agremiações podem nacionalizar a sua votação por razões não relacionadas ao ciclo eleitoral presidencial, concentrando esforços nas eleições para governador. Usando análises comparativas e estatísticas das estratégias partidárias, conclui-se que a combinação entre federalismo e coordenação eleitoral mediante barganhas intracoligação permite a sobrevivência de partidos provincializados que se nacionalizam por meio de estratégias nacionais e subnacionais fracamente integradas. Isso minimiza, por sua vez, potenciais efeitos sistêmicos da bipolaridade PT-PSDB na eleição presidencial.

Palavras-chave: nacionalização partidária; eleições presidenciais; presidencialismo de coalizão; federalismo; efeito "rabo de casaca"

\section{ABSTRACT \\ Party Nationalization and Electoral Strategies in Coalition Presidentialism}

This article explores the role of presidential elections and federalism in the nationalization of parties in Brazilian coalition presidentialism. It is argued that the strategic response of parties given the nationalizing incentives of presidential elections tends to vary significantly in multi-level systems, especially in the presence of a gubernatorial coattail effect. While some parties are successful in mobilizing the national electorate through "presidentialization" other groups may be capable of obtaining votes nationally for reasons that are unrelated to the cycle of presidential elections, concentrating efforts on gubernatorial elections. Using comparative and statistical analyses party strategies it was concluded that a combination between federalism and electoral coordination through bargaining within alliances allows the survival of provincialized parties that become national through national and sub-national strategies that are weakly integrated. This, in turn, minimalizes the potential systemic effects of the PT-PSDB bi-polarity in national elections.

Keywords: party nationalizations; presidential elections; coalition presidentialism; federalism; coattail effect 


\section{RÉSUMÉ}

Nationalisation des Partis et Stratégies Électorales dans le Présidentialisme de Coalition

Cet article analyse le rôle des élections présidentielles et du fédéralisme sur la nationalisation des partis au sein du présidentialisme de coalition brésilien. On soutient ici que la réponse stratégique des partis face au caractère national de l'élection présidentielle tend à varier significativement au sein de systèmes à plusieurs niveaux, et ce en raison de l'effet d'entraînement (effet "coattail"). Tandis que certains partis réussissent à mobiliser l'électorat national grâce à la "présidentialisation", d'autres nationalisent plutôt leur audience en dehors du cycle électoral présidentiel, en concentrant leurs efforts sur les élections aux postes de gouverneurs des différents États de la fédération. Moyennant des analyses comparatives et statistiques des stratégies partisanes, on a pu conclure que la combinaison entre fédéralisme et coordination électorale via des négociations internes aux coalitions permet la survie de partis provinciaux qui se nationalisent en fonction de stratégies nationales et subnationales faiblement intégrées. Cet état de fait minimise donc les éventuels effets systémiques de la bipolarité PT-PSDB qui marque les élections présidentielles.

Mots-clés: nationalisation des partis; élections présidentielles; présidentialisme de coalition; fédéralisme; effet "coattail"

\section{RESUMEN}

Nacionalización Partidaria y Estrategias Electorales en el Presidencialismo de Coalición

Este artículo explora el papel de las elecciones presidenciales y del federalismo sobre la nacionalización de los partidos en el presidencialismo de coalición brasileño. Se argumenta que la respuesta estratégica de los partidos frente a los incentivos de carácter nacional de la elección presidencial tiende a variar de forma significativa en sistemas multinivel, particularmente ante la presencia de un efecto "coattail". Mientras algunos partidos son exitosos en movilizar el electorado nacional a través de la "presidencialización", otros pueden nacionalizar su votación por razones que no están asociadas al ciclo electoral presidencial, concentrando esfuerzos en las elecciones para gobernador. Tras realizar análisis comparativas y estadísticas de las estrategias partidarias, se concluye que la combinación entre federalismo y coordinación electoral, mediante negociaciones inter-coaliciones, permite la sobrevivencia de partidos provincializados que se nacionalizan a través de estratégicas nacionales y subnacionales poco integradas. Esto minimiza, en cambio, potenciales efectos sistémicos de la bipolaridad PT-PSDB en la elección presidencial.

Palabras clave: nacionalización partidaria; elecciones presidenciales; presidencialismo de coalición; federalismo; efecto "coattail" 